\title{
The Construction and Practical Application of the Model for Analyzing the Contribution Degree of the Two Factors Affecting Sales
}

\author{
Wenwei Jin \\ China Tobacco Zhengjiang Industrial Co., LTD, \\ Hangzhou 310009, Zhengjiang
}

\begin{abstract}
In this paper, by decomposing the sales volume into two factors (i.e. the number of merchants replenishing stocks and the average number of the stocks replenished by merchants) from the angle of the sales volume composition, a model for analyzing the two factors affecting sales was constructed. By quantitatively analyzing the two factors, the contribution degree of the two factors to the changes of sales was dearly definedwhich factors to affect the change of sales were determined and also applied to guiding the late cigarette marketing, aiming to capture the focusing point and promote the marketing to develop in a targeted way.
\end{abstract}

Keywords- Affecting Factors; Two Factors; Contribution Degree Analysis; Application

\section{Introduction}

In the daily cigarette marketing, the volume of sales is a core key indicator. Seen from the composition of sales, the arithmetic product between the number of merchants replenishing stocks and the average number of the stocks replenished by merchants is the volume of sales. The sales cycle (i.e. week) popular in the current industry was used as unit; the volume of sales in a week was constituted by the arithmetic product between the number of merchants replenishing stocks and the average number of the stocks replenished by merchants.

The effect from the dynamic changes of the number of merchants replenishing stocks and the average number of the stocks replenished by merchants on sales was studied for indicating the sources of the main driving forces of the product market development and reflecting the market foundation of the product development. Therefore, the method of analyzing the effect degree from the number of merchants replenishing stocks and the average number of the stocks replenished by merchants on sales is supposed to be an effective tool of analyzing and recognizing the market and guiding the future work.

\section{The study and construction of the method model}

\subsection{Definition}

The contribution degree of the change of the number of merchants replenishing stocks in a week to the change of sales volume was expressed with the proportion of the sales volume change caused by the change of the number of merchants replenishing stocks in the total change of sales volume. The contribution degree of the change of the average number of the stocks replenished by merchants to the change of sales volume was expressed with the proportion of the sales volume change caused by the change of the average number of the stocks replenished by merchants in the total change of sales volume.

\subsection{Formulas}

2.2.1 Calculating the sales changes caused by the two factors respectively

The sales change caused by the number of merchants replenishing stocks in a week $=($ the number of merchants replenishing stocks in the current weak- the number of merchants 
replenishing stocks in the same week of last

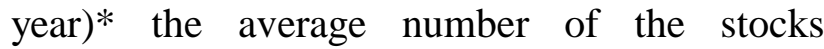
replenished by merchants in the same period of last year;

The sales change caused by the average number of the stocks replenished by merchants $=($ the average number of the stocks replenished by merchants in the current weekthe average number of the stocks replenished by merchants in the same week of last year)* the number of merchants replenishing stocks in the current weak

2.2.2 Calculating the contribution degrees of the sales changes caused by the two factors in the total sales change

The contribution degree of the number of merchants replenishing stocks in a weak=the sales change caused by the number of merchants replenishing stocks in a weak/the total sales change;

The contribution degree of the average number of the stocks replenished by merchants=the sales change caused by the average number of the stocks replenished by merchants/the total sales change;
The sum of the two factors' proportions was $100 \%$.

\subsection{Statistical method}

The observation point was based on the sum total in a week or a long period of time. The dynamic change could be observed weekly through the week analysis to reflect the dynamic change trends of the two factors' effect on sales. In a long period of time, the sum total was used as an observation object to reflect the total effect of the two factors on the change of sales.

\section{The empirical analysis of the model}

According to the above analysis model, an analysis was made using several cases.

\subsection{Case 1: Shenyang Marketplace Liqun (Yangguang)}

The contribution degrees of the two factors to the changes of sales in Shenyang Marketplace Liqun (Yangguang) from the 19th week to the 31th week (May 4 August 2) are shown in table 1.

Table 1

\begin{tabular}{|c|c|c|c|c|c|c|c|c|c|c|c|c|c|c|}
\hline Index & $\mathrm{n}$ total & $\begin{array}{c}19^{\text {th }} \\
\text { week }\end{array}$ & $\begin{array}{c}20^{\text {th }} \\
\text { week }\end{array}$ & $\begin{array}{c}21^{\text {th }} \\
\text { week }\end{array}$ & $\begin{array}{c}22^{\text {th }} \\
\text { week }\end{array}$ & $\begin{array}{c}23^{\text {th }} \\
\text { week }\end{array}$ & $\begin{array}{c}24^{\text {th }} \\
\text { week }\end{array}$ & $\begin{array}{c}25^{\text {th }} \\
\text { week }\end{array}$ & $\begin{array}{c}26^{\text {th }} \\
\text { week }\end{array}$ & $\begin{array}{c}27^{\text {th }} \\
\text { week }\end{array}$ & $\begin{array}{c}28^{\text {th }} \\
\text { week }\end{array}$ & $\begin{array}{c}29^{\text {th }} \\
\text { week }\end{array}$ & $\begin{array}{c}30^{\text {th }} \\
\text { week }\end{array}$ & $\begin{array}{c}31^{\text {th }} \\
\text { week }\end{array}$ \\
\hline Sales & 0 & 2.39 & 1.52 & 1.9 & 3.01 & 3.9 & 19.96 & 20.82 & 25.02 & 16.75 & 17.91 & 20.95 & 19.98 & 8.78 \\
\hline Sales Change (Box & 122.4 & 2.22 & 1.3 & 1.78 & 2.8 & 2.69 & 18.29 & 17.38 & 16.58 & 15.74 & 8.91 & 16.78 & 14.6 & 3.31 \\
\hline Change of the abov & 6.01 & 4.31 & 6.88 & 6.34 & 6.6 & -5.72 & 3.57 & -4.96 & -35.87 & -18.86 & -43.71 & 3.36 & -3.02 & 7.85 \\
\hline Sales change from merchants & 167.72 & 0.82 & 0.17 & 0.29 & 0.75 & 5.07 & 15.62 & 21.56 & 56.03 & 29.4 & 40.91 & 14.03 & 17.18 & 1.17 \\
\hline chance from & -45.33 & 1.4 & 1.13 & 1.5 & 2.06 & -2.38 & 2.67 & -4.18 & -39.45 & -13.66 & -32 & 2.75 & -2.58 & 2.13 \\
\hline Contribution of average stock change & -37.03 & 62.92 & 86.75 & 83.93 & 73.38 & -88.47 & 14.59 & -24.07 & -238 & -86.74 & -359 & 16.42 & -17.68 & 64.52 \\
\hline
\end{tabular}

When the comprehensive quality index was prepared, the quantity index during the reporting period was necessarily used as the same measurement factor.

(1) Laspeyres index in statistics was used for reference: the average number of the stocks replenished by merchants during the base period was used as the same measurement factor, and the weight was fixed in the base period.
(2) Paasche index was used for reference: the number of merchants replenishing stocks during the reporting period was used as the same measurement factor, and the weight was fixed in the reporting period.

Currently, the general principle in statistics for the same measurement factor in the base period was that the quality index during the base period was applied when the comprehensive quality index was prepared. 
Overall, the total sales increment in this period was 122.4 boxes, of which the increment brought by the number of merchants replenishing stocks in a weak was 167.72 boxes, and the increment brought by the average number of the stocks replenished by merchants was -45.33 boxes; the contribution degree from the change of the number of merchants replenishing stocks in a weak was $137.03 \%$, and the contribution degree from the change of the average number of the stocks replenished by merchants was $-37.03 \%$; the overall sales increment was brought from the unilateral expansion of the number of merchants replenishing stocks in a weak; the contribution from the average number of the stocks replenished by merchants was negative.

From the perspective of the changing trend every week, this period was divided into two sections: (1) 19th week to the 22th week; (2) the 23 th week to the 31 th week.

\subsection{Case 2: Nanchang Marketplace Liqun (Ruanzhangzui)}

The contribution degrees of the two factors to the change of sales in Nanchang Marketplace Liqun (Ruanzhangzui) from 19th week to the 31th week (May 4 August 2) are shown in table 2.

Table 2

\begin{tabular}{|c|c|c|c|c|c|c|c|c|c|c|c|c|c|c|}
\hline Index & total & $\begin{array}{r}19^{\text {th }} \\
\text { week } \\
\end{array}$ & $\begin{array}{r}20^{\text {th }} \\
\text { week }\end{array}$ & $\begin{array}{c}21^{\text {th }} \\
\text { week }\end{array}$ & $\begin{array}{r}22^{\text {th }} \\
\text { week }\end{array}$ & $\begin{array}{c}23^{\text {th }} \\
\text { week }\end{array}$ & $\begin{array}{c}24^{\text {th }} \\
\text { week }\end{array}$ & $\begin{array}{c}25^{\text {th }} \\
\text { week }\end{array}$ & $\begin{array}{r}26^{\text {th }} \\
\text { week }\end{array}$ & $\begin{array}{c}27^{\text {th }} \\
\text { week }\end{array}$ & $\begin{array}{r}28^{\text {th }} \\
\text { week } \\
\end{array}$ & \begin{tabular}{|c|}
$29^{\text {th }}$ \\
week \\
\end{tabular} & $\begin{array}{c}30^{\text {th }} \\
\text { week }\end{array}$ & $31^{\text {th }}$ \\
\hline$\underline{S}$ & & .66 & 53 & 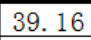 & ( & 0.06 & & 44 & 6 & 7 & E & 134.72 & & \\
\hline $\mathrm{S}$ & & 73.21 & -4.19 & & & 9.7 & & 2.78 & 24 & 56.88 & 96.22 & 120.29 & 3.52 & $0 T$ \\
\hline Merc & & & -683 & & & & 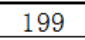 & 285 & 116 & -52 & & & 23 & 926 \\
\hline Chan & & 5.39 & 1.11 & 57 & 9.05 & 1.12 & 10.42 & 8.23 & 10 & 9.6 & 12 & 17.97 & 0.2 & 1.18 \\
\hline Sale & & 14.21 & -9.09 & -6.06 & -5.81 & 0.64 & 2.58 & 3.71 & 1.34 & -0.55 & 4.89 & 3.58 & 6.73 & 10.86 \\
\hline Sales & & 59 & 4.9 & 22.86 & 54.19 & 70.34 & 71.21 & 59.07 & 64.89 & 57.43 & 91.33 & 116.7 & 1. 79 & 11.48 \\
\hline Contribution of & & 9.41 & 216.87 & -36.09 & -12.01 & -0.91 & 3.5 & 5.91 & 2.02 & -0.97 & 5.08 & 2.98 & 79.04 & 48.62 \\
\hline$\frac{a t r}{a t r}$ & 96.32 & 80.59 & 110.9 & 36.08 & 12.01 & 100.91 & 96.5 & 94.08 & 97.97 & 00.97 & 4.91 & 97.02 & 20.96 & 51.37 \\
\hline
\end{tabular}

Overall, the total sales increment in this period was 710.96 boxes. It is necessary to note that the sales declined in the 20th week, the contribution degrees of the number of merchants replenishing stocks and the average number of the stocks replenished by merchants in the weak were $216.87 \%$ and $-116.87 \%$ respectively, suggesting the main factor resulting in the decline of the sales was the decline of the number of merchants replenishing stocks. The column diagram of the contribution degree of the number of merchants replenishing stocks in the week was above the zero graduation line, but its contribution to sales was negative.

\subsection{Case 3: Wuhan Marketplace Liqun (new version)}

The contribution degrees of the two factors to the change of sales in Wuhan Marketplace Liqun (new version) from the 24th week to the 31th week (June 8 September 6) are shown in table 3.

Table 3

\begin{tabular}{|c|c|c|c|c|c|c|c|c|c|c|c|c|c|c|}
\hline Index & In total & $\begin{array}{c}24^{\text {th }} \\
\text { week }\end{array}$ & $\begin{array}{r}25^{\text {th }} \\
\text { week }\end{array}$ & $\begin{array}{c}26^{\text {th }} \\
\text { week } \\
\end{array}$ & $\begin{array}{c}27^{\text {th }} \\
\text { week } \\
\end{array}$ & $\begin{array}{c}28^{\text {th }} \\
\text { week }\end{array}$ & $\begin{array}{r}29^{\text {th }} \\
\text { week }\end{array}$ & $\begin{array}{c}30^{\text {th }} \\
\text { week }\end{array}$ & $\begin{array}{c}31^{\text {th }} \\
\text { week }\end{array}$ & $\begin{array}{r}32^{\text {th }} \\
\text { week }\end{array}$ & $\begin{array}{c}33^{\text {th }} \\
\text { week }\end{array}$ & $\begin{array}{c}34^{\text {th }} \\
\text { week }\end{array}$ & $\begin{array}{c}35^{\text {th }} \\
\text { week }\end{array}$ & $\begin{array}{c}36^{\text {th }} \\
\text { week }\end{array}$ \\
\hline Sales (Boxes) & 2951.98 & 239.9 & 207.6 & 213.5 & 171 & 204 & 211.7 & 209.7 & 220.2 & 182.2 & 198 & 268.3 & 279.6 & 346.3 \\
\hline Sales Change (Boxes) & 1248.06 & 55.81 & 81.14 & 80.62 & 70.76 & 28.28 & 88.77 & 82.21 & 118.5 & 83.09 & 90.24 & 152.8 & 135.4 & 180.5 \\
\hline \begin{tabular}{|l} 
Merchants replenishing stocks \\
\end{tabular} & 105592 & 1973 & 8585 & 8061 & 8949 & 3384 & 10286 & 9099 & 10693 & 10516 & 9647 & 12022 & 8296 & 4081 \\
\hline \begin{tabular}{|l|} 
Change of the above merchants \\
\end{tabular} & 0.29 & 0.4 & 0.1 & 0.04 & 0.01 & 0 & -0.04 & -0.03 & 0.21 & 0.12 & 0.13 & 0.49 & 0.53 & 1.44 \\
\hline Sales change from merchants & 896.61 & 15.87 & 71.74 & 77.34 & 70.03 & 27.94 & 93.04 & 84.87 & 100.4 & 70.93 & 78.59 & 103.3 & 89.23 & 30.99 \\
\hline Sales change from average stock & 351.45 & 39.95 & 9.39 & 3.28 & 0.73 & 0.35 & -4.27 & -2.66 & 18.1 & 12.16 & 11.65 & 49.48 & 46.14 & 149.5 \\
\hline \begin{tabular}{|l} 
Contribution of merchants change \\
\end{tabular} & 71.84 & 28.43 & 88.42 & 95.93 & 98.97 & 98.77 & 104.8 & 103.2 & 84.73 & 85.36 & 87.09 & 67.6 & 65.92 & 17.17 \\
\hline Contribution of average stock change & 28.16 & 71.57 & 11.57 & 4.07 & 1.03 & 1.23 & -4.81 & -3.23 & 15.27 & 14.64 & 12.91 & 32.39 & 34.08 & 82.83 \\
\hline
\end{tabular}


Overall, the total sales increment in this period was 1248.06 boxes, of which the increment brought by the number of merchants replenishing stocks was 896.61 boxes, and the increment brought by the average number of the stocks replenished by merchants was 351.45 boxes; the proportion of the change of the number of merchants replenishing stocks was $71.84 \%$, and the proportion of the change of the average number of the stocks replenished by merchants was $28.16 \%$.

Seen from the weekly situation, the contribution degrees of the two factors to the change of sales were positive except in the 29th week and the 30th week; the contribution from the number of merchants replenishing stocks was primary, so the elementary marketing foundation was effectively laid.

\section{The guiding significance of the statistical study based on the market basis analysis to the relevant work}

\subsection{Clearly judging the market basis}

By analyzing the contribution degrees of the two factors to the change of sales, the factor to mainly result in the change of sales could be clearly judged. This provided a reference for the market basis judgment.

\subsection{The guiding significance to the basic work}

Only if the market basis was clearly judged, guidance could be available for the late basic work. The following four questions were totally summarized:

Was the volume of sales increasing or decreasing?

Which was the main factor to result in the sales increase or decrease?

Where were the late development opportunities for the products according to the current changes and what were possible questions?

What was the late focus after opportunities and problems were obvious?

\section{The guidance and application of the model}

\subsection{Providing a basis for the focus of the late basic work}

If the increase of sales mainly sourced from the number of merchants replenishing stocks and also the rates of the two factors were higher, commercial corporations were cooperative to enlarge the rational quantitation on the basis of promoting the number of merchants replenishing stocks late, aiming to improve the average number of the stocks replenished by the retailers and seek a duel development in both market breadth and depth.

If the increase of sales mainly sourced from the expansion of the number of merchants replenishing stocks and also the rates of the two factors were lower, this suggested the demand was expanded, but the retailers had intention to order more products under the currently reasonable quantitative level, so the late work focus was necessarily placed on promoting the consumption through the product marketing, and increasing the retailers' intention to order more products and the average number of the stocks replenished by merchants.

If the increase of sales mainly sourced from the expansion of the average number of the stocks replenished by merchants and also the rates of the two factors were lower, this suggested the demand was not effectively expanded and also the retailers' intention to order more products was weak, so the late work focus was necessarily placed on lowering the reasonable quantitation and actively promoting the improvement of the number of merchants replenishing stocks.

If the increase of sales mainly sourced from the expansion of the average number of the stocks replenished by merchants and also the rates of the two factors were higher, this suggested the late work focus was necessarily on cooperating commercial corporations and specifically promoting the sustainable improvement of the number of merchants replenishing stocks. 
The above tool played a guiding role in the basic market work and could be widely applied to the actual marketing work, and this was illustrated below. From the analysis on the two factors affecting the sales of Nanchang Marketplace Liqun (Ruanzhangzui), the increase of the sales from the 19th week to the 31th week was basically originated from the increase of the average number of the stocks replenished by merchants, and the contribution degree of the number of merchants replenishing stocks was very small. Based on the above analysis, the business team discovered the shortcomings in promoting the number of merchants replenishing stocks. On this basis, this team cooperated with commercial corporations: the cooperative marketing to promote the number of merchants replenishing stocks was implemented from September concerning about Liqun (Ruanzhangzui) by relying on the main commercial channels, so as to emphatically improve the number of merchants replenishing stocks.

Through cooperative promotion, the number of merchants replenishing stocks in Nanchang Marketplace Liqun (Ruanzhangzui) was boosted, and the contribution degrees of the two factors to the change of sales from the 36th week to the 44th week (August 31 November 1) are shown in table 4.

Table 4

\begin{tabular}{|c|c|c|c|c|c|c|c|c|c|c|}
\hline Index & In total & $36^{\text {th }}$ week & $35^{\text {th }}$ week & $38^{\text {th }}$ week & $39^{\text {th }}$ week & $\begin{array}{c}40^{\text {th }} \\
\text { week }\end{array}$ & $41^{\text {th }}$ week & $42^{\text {th }}$ week & $43^{\text {th }}$ week & $44^{\text {th }}$ week \\
\hline Sales (Boxes) & 235.59 & 26.17 & 35.09 & 32.1 & 29.14 & 11.02 & 33.63 & 20.16 & 26.34 & 21.94 \\
\hline Sales Change (Boxes) & 163.37 & 5.56 & 17.49 & 27.31 & 21.12 & 9.9 & 27.56 & 13.03 & 19.46 & 21.94 \\
\hline Merchants replenishing stocks & 13174 & 1270 & 2058 & 2503 & 2136 & 753 & 1860 & 1327 & -62 & 1329 \\
\hline Change of the above merchants & 0.8 & -0.63 & -0.2 & 1.08 & 0.61 & 1.66 & 1.49 & 0.6 & 3 & 2.12 \\
\hline Sales change from merchants & 86.21 & 13.6 & 20.52 & 12.2 & 12.64 & 3.15 & 7.74 & 6.01 & -0.25 & 10.63 \\
\hline Sales change from average stock & 77.16 & -8.04 & -3.03 & 15.1 & 8.48 & 6.75 & 19.82 & 7.02 & 19.71 & 11.3 \\
\hline Contribution of merchants change & 52.77 & 244.53 & 117.29 & 44.69 & 59.84 & 31.79 & 28.08 & 46.14 & -1.28 & 48.47 \\
\hline Contribution of average stock & 47.23 & -144.5 & -17.29 & 55.31 & 40.16 & 68.21 & 71.92 & 53.86 & 101.28 & 51.53 \\
\hline
\end{tabular}

Note: Three targeted indexes referred to the number of the merchants replenishing stocks, the percentage of the merchants replenishing adequate stocks, and the rate of merchants replenishing adequate stocks. The number of merchants replenishing adequate stocks referred to the proportion of the retailers replenishing adequate stocks in the total retailers qualified to order more products. The rate of the merchants replenishing adequate stocks referred to the ratio between the actual order quantity and the maximum theoretical order quantity under the weekly reasonable quantitative policy. The reasonable weekly quantitation referred to the maximum order quantity available for different grades of retailers. Three targeted indexes reflected the enthusiasm of retailers for ordering cigarette products; higher values of the three targeted indexes meant the retailers' intention to order was fiercer, and otherwise lower.

By comparing the two periods from the 19th week to the 31 th week and from the 36 th week to the 44th week, the following changes were found. The change of the number of merchants replenishing stocks was as follows: the number increased from 164 (the 19th week $\sim$ the 32th week) to 1464 (the 36th week the 44th week), increasing by 1300 at average. The change of the contribution degrees of the two factors was as follows: the one-way contribution from the average number of the stocks replenished by merchants (the 19th week the 31th week) changed to the two-way, positive contribution from the two factors.
Seen from the above two compared changes, the second sales increase way was more healthy and benign and played a more positive role in the sustainable development of the products. The model for analyzing the contribution degree of the two factors affecting sales played an important role in judging the basic market conditions and guiding the specific work, and this was fully embodied in this case. 


\subsection{Providing a basis for planning the goal of the number of merchants replenishing stocks}

In the daily process of planning the goal of the number of merchants replenishing stocks, the targeted influence degree of the late number of merchants replenishing stocks was planned according to the current situation and the sales target, so as to provide a reference for planning the goal of the number of merchants replenishing stocks.

Liqun's plan for the goal of the number of merchants replenishing stocks in the second half of 2015 outside the province (except Zhejiang) was taken for example, and the concrete model was stated below.

Step 1: According to the above analysis, the contribution degree from the change of the number of merchants replenishing stocks in the first half year to the change of the sales was calculated.

The contribution degree from the number of merchants replenishing stocks in Liqun (new version) in the first half year was $29.98 \%$.

Step 2: According to the contribution degree from the change of the number of merchants replenishing stocks in the first half year to the change of the sales, the goal of the contribution degree in the second half year was planned, and it could be set by combining with the actual situation.

According to the current development situation in the first half year, the contribution degree of the number of merchants replenishing stocks in Liqun (new version) in the second half year was up to $35 \%$.

Step 3: According to the sales target and the targeted contribution degree of the number of merchants replenishing stocks in the second half year and the retrodict algorithm, the goal of the number of merchants replenishing stocks was calculated.

The Liqun (new version) sales target in the second half year was 705,400 boxes, and the sales volume in the second half of last year was 600,100 boxes, so an increase of 105,300 boxes was realized.

According to the targeted contribution degree $35 \%$ of the number of merchants replenishing Liqun (new version) in the second half year, the change of the sales brought by the improvement of the number of merchants replenishing stocks in the second half year was calculated as follows: $105300 * 35 \%=36855$ boxes.

According to the formula calculating the change of the sales brought by the number of merchants replenishing stocks, the accumulated goal of the number of merchants replenishing stocks in the second half year was calculated: the accumulated goal of the number of merchants replenishing stocks in the second half year=(the targeted sales change brought by the number of merchants replenishing stocks in the second half year/the average number of the stocks replenished by merchants in the second half of last year)+the accumulated number of merchants replenishing stocks in the second half of last year $=(36855 * 250 / 3.64)+39922230=42453480$ (merchants).

To promote the increase of the number of merchants replenishing stocks was a gradual step, so it was impossible to finish the goal immediately. Based on the number (1454201) of the merchants replenishing stocks in the 26th week, the targeted number of merchants replenishing stocks week by week in the second half year was planned according to the year-end isometric growth principle, as shown in table 5. 
Table 5

\begin{tabular}{|c|c|c|c|c|c|c|c|c|c|}
\hline Week & $27^{\text {th }}$ week & $28^{\text {th }}$ week & $29^{\text {th }}$ week & $30^{\text {th }}$ week & $31^{\text {th }}$ week & $32^{\text {th }}$ week & $33^{\text {th }}$ week & $34^{\text {th }}$ week & $35^{\text {th }}$ week \\
\hline \begin{tabular}{|c|} 
Targeted \\
Merchants \\
teplenishing stocks
\end{tabular} & 1467432 & 1480664 & 1493895 & 1507127 & 1520358 & 1533590 & 1546821 & 1560053 & 1573284 \\
\hline Week & $36^{\text {th }}$ week & $37^{\text {th }}$ week & $38^{\text {th }}$ week & $39^{\text {th }}$ week & $40^{\text {th }}$ week & $41^{\text {th }}$ week & $42^{\text {th }}$ week & $43^{\text {th }}$ week & $44^{\text {th }}$ week \\
\hline \begin{tabular}{|c|} 
Targeted \\
Merchants \\
replenishing stocks
\end{tabular} & 1586516 & 1599747 & 1612979 & 1626210 & 1639442 & 1652673 & 1665905 & 1679136 & 1692368 \\
\hline Week & $45^{\text {th }}$ week & $46^{\text {th }}$ week & $47^{\text {th }}$ week & $48^{\text {th }}$ week & $49^{\text {th }}$ week & $50^{\text {th }}$ week & $51^{\text {th }}$ week & $52^{\text {th }}$ week & \\
\hline \begin{tabular}{c|} 
Targeted \\
Merchants \\
replenishing stocks
\end{tabular} & 1705599 & 1718831 & 1732062 & 1745294 & 1758525 & 1771757 & 1784988 & 1798220 & \\
\hline
\end{tabular}

\section{Conclusion}

In this paper, the construction and application of the model for analyzing the contribution degrees of the two factors affecting the volume of sales provided a new method for people to analyze the market and guide the work. In this model, the relatively abstract volume of sales was decomposed into two factors (i.e. the number of merchants replenishing stocks and the average number of the stocks replenished by merchants); the current situation of the product development market basis was evaluated using quantitative analysis; the late marketing focus was analyzed and clearly defined, aiming to promote the late marketing objects to be much clearer, the target to be quantitative, and the effect to be significant. Therefore, this model is of great promotion value.

\section{Acknowledgement}

Project Name: The Construction and Practical Application of the Model for Analyzing the Contribution Degree of the Two Factors Affecting Sales

Level: The Science and Technology Project of China Tobacco Zhengjiang Industrial Co., LTD (No.8100564)
Members: Wenwei JIN, Yong XU, Dechun ZHANG, Jianmin CHENG, Wenbin MO, Xiaofeng LEI, Ningguo LOU, Xiaofeng YANG, Jianqing XU, Xiaona WANG

\section{References}

[1] Ming Yang, Pinghua Zeng, Lixiang Zhang. Statistics Theory $[\mathrm{M}]$. Beijing: Electronic Industry Press, August 2014, Version 1.

[2] Weigang Meng. Liqun Brand Word-of-mouth Communication Strategy Research and Application [M]. Hangzhou: Hangzhou University Press, 1 December 2014.

[3] Wuchao Liang, Youyin Gu, Ningdong Duan. Study on China's High-end Cigarette Products Sales Prediction [J]. Value Engineering, 29, 2012.

[4] Hongmei LI, Jianhe Cao. Analysis on the Application of Data Mining Technology to the Tobacco Sales Industry [J]. The Modern Commercial Industry, 14, 2011. 